\title{
1 Native plants for greening Mediterranean agroecosystems
}

2 Borja Jiménez-Alfaro ${ }^{1 *}$, Stephanie Frischie ${ }^{2,3,4}$, Juliane Stolz ${ }^{2,5}$ \& Cándido Gálvez-

$3 \quad$ Ramirez $^{2}$

$4{ }^{1}$ Research Unit of Biodiversity (CSIC/UO/PA), Oviedo University, Campus de Mieres,

5 Mieres 33600, Spain.

$6 \quad{ }^{2}$ Semillas Silvestres S.L., C/ Aulaga n²4, Córdoba 14012, Spain.

$7 \quad{ }^{3}$ Department of Earth and Environmental Sciences, University of Pavia, Corso Str.

8 Nuova, 65, 27100 Pavia PV, Italy.

$9{ }^{4}$ Xerces Society for Invertebrate Conservation, 628 NE Broadway Suite 200, Portland, 10 OR 97232, USA.

$11{ }^{5}$ Technische Universität Dresden, Chair of Forest Growth and Woody Biomass

12 Production, Pienner Straße 8, 01737 Tharandt, Germany. 
In the upcoming UN Decade on Ecosystem Restoration, a global challenge for scientists and practitioners will be to develop a well-functioning seed production sector based on a sound species-selection process ${ }^{1}$. To balance crop production with biodiversity functions in Mediterranean woody crops, agroecological practices ${ }^{2}$ suggest the need to move towards the establishment of herbaceous ground covers ${ }^{3-5}$. However, establishing such plants requires a supply of suitable native seeds which is currently unavailable. Here, we present a comprehensive process for selecting regionally-adapted species that also emphasizes considerations for seed production ${ }^{6}$. Using olive groves as a target system, we found that research on ground covers for regenerative agriculture has largely overlooked native species at the expense of commercial and ill-suited varieties. Our assessment of native annuals showed that $85 \%$ of the grasses and forbs evaluated exhibit a suite of ecological and production traits that can be tailored to meet the requirements of farmers, seed producers and environmental agencies. These findings suggest that many native species are currently neglected in agronomic research, despite they are potentially suitable for ground covers and for supporting a nature-based solution ${ }^{7}$ in restoration practice. The framework used here may be applied in other agroecosystems to follow global greening initiatives and to support native seed production to scale up restoration ${ }^{8,9,10}$.

Agricultural intensification of Mediterranean woody crops (vineyards, olive groves and fruit trees) has dramatically changed traditional landscapes that were relatively sustainable until the 20th century ${ }^{11}$. Olive groves (Olea europaea L.) are a quintessential example of agroecosystems suited for regenerative practices ${ }^{12}$ because they are perennial cultural systems currently degraded by erosion, desertification and biodiversity loss ${ }^{3}$. Olive groves range from traditional to intensive and very-intensive production systems. In most cases, the use of fertilizers, suppression of non-crop vegetation and modern irrigation practices have maximized olive production at the cost of soil health, compromising the sustainability of a strategic economic sector in Mediterranean countries ${ }^{13}$. In turn, the combination of tillage and herbicide use has led 
to large expanses of bare soil ${ }^{14}$ through the loss of herbaceous layers that covered olive groves for centuries. These practices increase dependence on water and the progressive loss of soil organic matter, leading to the need to restore ground covers and balance crop production with the preservation of natural and cultural services ${ }^{15}$. It has been widely suggested that commercial varieties used for ground covers are illsuited for the Mediterranean climate and compete with the crop for soil moisture, while native species, especially winter annuals, might provide the benefits of ground covers without the negative aspects of exotic species ${ }^{13,16}$.

We established an evaluation process to identify native plants with potential for restoring agroecosystems to meet sustainability targets (Fig. 1). Our framework is based on the untested premise that native plants may be ideal ground covers because they have better ecological fit with the system, assuming they can be farmed to produce an adequate amount of seeds for establishing and restoring ground covers. As the first step, we reviewed the literature of the last 30 years to assess the use of native plants in agroecological research for restoring the herbaceous cover of olive groves in Mediterranean countries (see State of the art in Methods). From a total of 50 studies evaluated, $68 \%$ focused on ground cover performance and effects on soil erosion or soil water using commercial species (Fig. 2). These studies analysed 42 forage or domesticated crop varieties (45\% Fabaceae, 31\% Poaceae and 14\% Brassicaceae) from species which are exotic to the regions where they were used (Supplementary Table 1). The other $32 \%$ of studies evaluated a total of 20 species native to the study regions, in most cases grasses and forbs (55\% Poaceae, 20\% Fabaceae and 15\% Brassicaceae). While all the studies on native plants assessed ecological traits relevant to their value as ground covers (e.g. self-sowing, height development, growth form, herb cover, root development or $\mathrm{N}$-fixation), none of them considered seed farming potential. This is an important research gap because the need of a seed supply is a priority for establishing ground covers ${ }^{16,13}$. Indeed, a current global challenge is how to scale up restoration by using large amounts of seeds from native plants to satisfy future demand $^{10}$, a crucial issue for the upcoming UN Decade on Ecosystem Restoration. In 
Europe, the whole sector for the production of herbaceous native seeds is underdeveloped for producers and users ${ }^{17}$, limiting the implementation of agroecological practices.

In the second step, we defined the 'agroecosystem species pool' as the set of wild species that is known to occur naturally in the target system, assuming a portion of these species will be suitable for agroecological restoration (Fig. 1, see Species filtering in Methods). As a case study, we investigated the agroecosystem species pool of olive groves in the Spanish province of Córdoba (Andalusia), which has a key role in the global olive market ${ }^{18}$. From a total of 979 taxa of the regional flora reported to occur in traditional olive groves ${ }^{19}$, we collected life-form traits and species distribution ranges to filter the list to 303 species which are (i) annuals and (ii) native to the Mediterranean Basin (see Data Availability). Annual plants are desirable because they will naturally senesce at the onset of the summer dry season and persist as seeds. This reduces competition with the crop for soil moisture and reduces the requirement that farmers actively manage the ground cover, which regenerates from the seed bank at the onset of the autumn rains, when protection from erosion is needed. Nativity to the Mediterranean Basin is also important because not only will the species be adapted to the climate and farming cycles, but the plants will host and support pollinators (for the ground cover and adjacent crops) and beneficial insects as biological pest control ${ }^{20}$. We compiled up to six ecological traits to assess the suitability of native species for olive farming (see Suitability Index in Methods) and evaluated these traits in 10 grasses and 30 forbs that passed the above filters and were found in wild populations. Such evaluation (Table 1) showed that most of the species are ecologically suitable ("Good", "Fair" or "Excellent") for ecological restoration in the study system.

Our process then looked at production traits to estimate the suitability of species for seed farming, i.e. how they respond to the requirements of agronomic practices for producing cost-effective seed lots and generating a commercial seed supply. When grown in seed production fields (see Agronomic experiments in Methods), we found that 8 grasses and 27 forbs (out of 10 and 30, respectively) show good establishment 
and developed to reproductive maturity (Fig. 3). The grasses showed slight differences in phenology, with Cynosurus echinatus, Trachynia distachya, and a commercial variety of $L$. multiflorum, ripening later than the other grass species. Forbs were more variable in their development, with 13 out of 29 species reaching fruit maturity in July (after 29 weeks), while the other species matured later. These results indicate relatively similar seasonality and an optimal seed harvest time in early summer (June-July) for grasses and forbs sown in December.

The evaluation of production traits based on the experimental fields showed that most of the species are suitable for seed farming (Table 1). We also looked at fruit height and seed yield, which are critical traits for cost-effective production, determining the feasibility of mechanical harvesting and the quantity of seeds per area, respectively. We found that all native grasses and 24 forbs produced fruits at suitable height (taller than $10 \mathrm{~cm}$ ) for mechanized harvest (e.g. with a combine harvester). We found large differences (six orders of magnitude) within the seed yield of grasses, with the highest values for the native grass Trachynia distachya and the lowest for the commercial variety of L. multiflorum. Within forbs, differences were even larger (18 orders of magnitude), with a clear difference between families with small- and largeseeded species (see Data Availability).

Using the data collected for the selected species, we created a final suitability index that combined ecological and production traits (Table 1). Although both groups of traits may be assessed independently, here we looked at combined suitability for olive farming and seed farming. From a total of 35 species evaluated, 26 were defined as "Excellent" or "Good", seven were defined as "Fair" and two were "Poor" or "Fair/Good". The grasses were equally distributed from "Fair" to "Excellent", with the species of Anisantha and Hordeum ranking highest. Although some of the study species have been previously evaluated as ground covers (see Supplementary Table 1), our study demonstrates how the agronomic traits of these species make them suitable for seed farming. Moreover, we identified more than 20 species which have not been used before for greening Mediterranean olive groves, suggesting that many other species 
from the agroecosystem species pool (not evaluated here) are potentially suitable for ground cover restoration. Since our seed collection was performed in a relatively dry year (see Methods), it is possible that the evaluated species have specific traits for regeneration with low soil moisture. An ideal follow-up of the evaluation process should therefore repeat field collections to account for the natural dynamics of Mediterranean annual communities in response to inter-year climate variability.

We note that some of the evaluated species can be considered weeds by farmers ${ }^{21}$ and may have been subjected to eradication in olive groves in the Mediterranean Basin. Since many farmers may be reluctant to re-establish wild species $^{22}$, the adoption of native species as ground covers will require outreach and education activities to meet global policy on restoration (Fig. 1). As a proof of concept, a pilot study conducted on a conventional olive grove in our study region showed that a subset of the species predicted as potentially suitable in this study performed well during the following growing season, developing a soil seed bank with potential of plant regeneration ${ }^{23}$. Nevertheless, the performance of specific monocultures or seed mixtures may change under different environmental conditions or restoration aims (e.g. when a given function want to be prioritized). Although our index provides a set of provide a set of native plants with suitable characteristics to meet the requirements of seed producers and ecological restoration of Mediterranean woody crops. This is also the first study to include production traits of native plants in a comprehensive assessment of species selection, thus combining ecological and agronomical targets. maximizes cost-effectiveness in seed production areas ${ }^{6}$. Similar approaches between academia and conservation agencies will be essential in restoration programs 
developed by private and public partnerships to develop nature-based solutions based on native seed markets ${ }^{10}$. Such programs also will need to deal with issues related to policy targets (e.g. investing research efforts on priority systems by considering regional or national regulations) $)^{10}$ and restoration practice (e.g. designing seed provenance for selected species and developing infrastructures to scale up restoration projects) $)^{1}$. Our evaluation process also provides a link between agronomic research and seed producers, which is one of the major limitations of seed-based restoration ${ }^{17,24}$. The evaluation of agronomic traits shall further complement the research agenda of seed-trait ecology ${ }^{25}$. Although the specific traits to be used and the way they are combined may diverge largely depending on the target habitats and onsite experiments, implementing a process as the one presented here is a necessary step to identify and produce commercial native seed supplies on agroecosystem restoration.

\section{Methods}

State of the art. Olive groves are one of the most important agroecosystems in the Mediterranean region due to great socioeconomic impact and the large surface area they cover, with 10,527,502 ha of land under production in 2017 (97\% of the global area used for this crop $)^{26}$. However, the use of unsustainable soil management practices over the past decades threaten the sustainability of these agroecosystems ${ }^{27}$. One of the most important threats is soil erosion by water which leads to land degradation and desertification ${ }^{28}$. To ameliorate this situation, ground cover is the best method to control erosion by covering the soil either with inert matter or live plants ${ }^{29}$. While the grasses are expected to provide the root structure and surface cover to protect soil from erosion and $\mathrm{drought}^{28}$, the forbs, depending on the species, promote nitrogen fixation and additional functions such as interactions with pollinators, beneficial insects, and other wildlife ${ }^{13,30}$.

When an olive farmer wishes to sow and establish ground covers, the species available in the market are commercial forage varieties that were not selected for this 
system. Wild native species are expected to provide more benefits to the farmer and the agroecosystem, but they are rarely used due to the scarcity of seeds in the market. To address the extent of this problem, we searched for publications focusing on ground covers in olive groves of the Mediterranean region. In May 2015, we queried the Google Scholar database with the search criteria: 'ground covers' AND 'cover crops' AND ‘olive’ AND ‘Mediterranean’ AND ‘Europe’ since 1985. From c. 17.000 articles, we manually checked the title of the publications and selected those that clearly referred to the topic. We then compiled a list of taxa used as ground cover, which were split into: (i) commercial species of any geographical distribution that are available in the market as (mostly undefined) varieties and (ii) wild species that are native to the Mediterranean regions where olive trees are cultivated. We also looked at reports and proceedings cited in the selected articles, since most of the studies were useless or did not mention the species used. This resulted in 50 publications focused on olive groves plant families represented within each group (Fig. 2).

Species filtering. We defined the agroecosystem species pool as the set of species within fields) and applied a series of filters using information from regional and Spanish floras. Because seeds will be used as the propagule and because we are interested in

212 herbaceous plants, we removed ferns and woody vascular plants (mainly from

213 Equisetaceae, Salicaceae, Fagaceae, Ulmaceae, Moraceae, Santalaceae,

214 Simaroubaceae, Anacardiaceae, Rhamnaceae, Thymelaeaceae, Tamaricaceae, 
range is outside the Mediterranean Basin. Our definition of native plants includes archaeophytes (i.e. species that might have been introduced before 1500 A.D. and are now naturalized). These taxa are adapted to the regional climate and they are presumed to have the most potential for trophic interactions (e.g. with pollinators). We then filtered out taxa to keep winter annuals, because they persist and regenerate in seasonally dry and disturbed habitats ${ }^{31}$ and because they have short life cycles and naturally senesce in spring. Therefore, winter annuals will be self-sowing and won't compete for water with the olive trees during the dry summer season. Some of the selected species can function as biennials or short-lived perennials, but they were included in the evaluation because they mostly behave as therophytes in the study system. Some of them (e.g. Anthyllis vulneraria, Antirrhinum bellidifolium, Salvia verbenaca, and Scabiosa atropurpurea) also have been identified as hosts for beneficial insects ${ }^{32}$.

Field sampling. In 2015, we conducted a field survey to collect seeds from wild populations of any of the pre-selected species in the Spanish province of Córdoba and ecologically similar environments in the nearby province of Jaén. According to the data of the Spanish Agency of Meteorology (www.aemet.es) for the Córdoba airport in 2015, this year was c. $50 \%$ drier than the average of the last decade. We prioritized the collection of different taxonomic families but defined between $20 \%$ and $25 \%$ of target taxa to be grasses (Poaceae) because of their structural importance as ground covers. After several field campaigns looking for any of the selected species, we collected a sufficient number of seeds for 10 grasses and 30 forbs in a total of 66 sites. We sampled a minimum of two populations for each species with a minimum of 500 individuals/population and collected seeds from at least 100 haphazardly selected individuals/population, following the standards of the ENSCONET protocol ${ }^{33}$. In the study region, natural populations available for initial collection of foundation seeds are not threatened or legally protected, and they are relatively abundant. In a set of germination experiments, we confirmed that all the study species behave as winter annuals and they are expected to germinate in autumn $n^{34,35}$, a desired condition for 
avoiding water competition with olive trees in summer. The remaining seeds were stored under ambient conditions until field experiments started.

247

Agronomic experiments. To evaluate production traits for seed farming, we conducted a field experiment for grasses and forbs from November 2015 to June 2016 on farmland southwest of Córdoba (Spain) near the Guadalquivir River (37.829741 ${ }^{\circ}$ Latitude, $-4.905091^{\circ}$ Longitude). The site is part of an agricultural area for production of herbaceous crops and orange orchards. The field trials were conducted in a flat, uniform field with a single soil type (sandy loam). The plots were arranged as randomized blocks with 3 repetitions for each species (Supplementary Fig. 1). The sowing of grasses and forbs took place on 3 consecutive days starting on the 30th November 2015. A lawn roller was used to increase the soil-seed contact. For comparative purposes, we also sowed a commercial variety of Italian ryegrass (Lolium multiflorum Lam. var. westerwoldicum Wittm) which is largely available in the seed market of Mediterranean countries and one of the first choices of olive farmers for ground cover. To assess traits important to mechanized seed farming, we monitored the development and seedling establishment of the recruits every two weeks. We also monitored plant development and provided supplemental irrigation (c. $20 \mathrm{l} / \mathrm{m}^{2}$ ) two times during spring 2016 to ensure that the plants completed their cycle in dry periods. This is a common practice in rainfed agriculture, and it is also the regular procedure for seed farming in the study area.

We adapted the $\mathrm{BBCH}$ system ${ }^{36}$ to code the phenological growth stages of both forbs and grasses. We then recorded growth habit to determine the suitability for mechanized harvest and measured two quantitative traits that cannot be inferred from the literature: (i) minimum fruit height above the soil when seeds are about to disperse, determining the feasibility of mechanical harvesting, and (ii) seed yield as the seed number per $\mathrm{m}^{2}$. For the grasses, the number of seeds was calculated from the number of spikes counted in $1 \mathrm{~m}^{2}$ and the average number of seeds per spike found in 10 single spikes for each species and each replicate. For the forbs, we estimated the number of seeds from the total weight per lot and species, using the 1000 -seed-weight 
ratio provided by the Seed Information Database ${ }^{37}$. Three forb species (Anarrhinum bellidifolium, Helianthemum ledifolium and Tuberaria guttata) and two grass species (Aegilops geniculata and $A$. triuncialis) did not grow well for measuring agronomic traits, therefore they were not further evaluated.

Suitability Index. Scoring native plants based on seed collection or biological attributes is a method to optimize the use of seed lots for restoration ${ }^{38}$. Here, we used the free software DEXi ${ }^{39}$ to estimate the potential suitability of the 40 evaluated grasses and forbs for both olive farming and seed farming, based on ecological and production traits, respectively. DEXi has been used to support complex decision making where factors may be competing, including agroecological applications ${ }^{40}$. The program uses as fundamental terms: options, attributes, values, functions and evaluations. Options are the possible selections; in this case, each native species. An attribute is the characteristic of interest. For each attribute, an option has a value, which is organized as a qualitative scale: "low", "medium”, "high”. First, we defined and organized 16 attributes based on existing literature (see Supplementary Table 1 and references) for both grasses and forbs, namely: (1) trafficability (plant height), (2) seasonal growth, (3) growth habit, (4) non-competitive for water, (5) non-competitive for nitrogen (6) nonhost for Verticillium pathogen (7) seed size, (8) seed shape, (9) fruit height, (10) harvest window, (11) seed dehiscence (separation from fruits), (12) seed separation (from inert material), (13) fruit shattering, (14) dispersal window, (15) seed yield, and (16) demand in the market. We then input these to DEXi to build a hierarchy of base attributes (which we input data values for) and aggregated attributes (traits) in two major functions: suitability for olive farming (based on ecological traits, 1-6) and suitability for seed farming (based on production traits, 7-16). Once the branch structure was defined, we created a scale for each attribute (e.g. "Poor"-"Fair"-"Good""Excellent") and input the values for each option. The attributes were assigned based on data from the literature or from our laboratory and agricultural experiments (see Data Availability). For each aggregate attribute, we defined a matrix of function rules, which DEXi uses to calculate the value of the aggregate attribute using the default 
parameters. Although DEXi is based on qualitative attributes, it calculates indirect weights for setting a utility function to find a multi-criteria solution. We ran the software to generate the Suitability Index for olive farming, seed farming, and their combination.

Data availability. The data for species pools, production traits (numerical), species assessment, and a copy of the DEXi evaluation file are archived at https://doi.org/10.5281/zenodo.3460431.

\section{References}

1. Gibson-Roy, P. Restoring grassy ecosystems - Feasible or fiction? An inquisitive Australian's experience in the USA. Ecol. Manag. Restor. 19, 11-25 (2018).

2. FAO. Agroecology To Reverse Soil Degradation and Achieve Food Security. International Year of Soils (2015).

3. Gómez, J. et al. Olive Cultivation, its Impact on Soil Erosion and its Progression into Yield Impacts in Southern Spain in the Past as a Key to a Future of Increasing Climate Uncertainty. Agriculture 4, 170-198 (2014).

4. Gómez, J. A. et al. The effects of cover crops and conventional tillage on soil and runoff loss in vineyards and olive groves in several Mediterranean countries. Soil Use Manag. 27, 502-514 (2011).

5. Rey, P. J. Preserving frugivorous birds in agro-ecosystems: lessons from Spanish olive orchards. J. Appl. Ecol. 48, 228-237 (2011).

6. Merritt, D. J. \& Dixon, K. W. Restoration Seed Banks-A Matter of Scale. Science (80-. ). 332, (2011).

7. Cohen-Shacham, E., Walters, G., Janzen, C. \& Maginnis, S. Nature-based solutions to address global societal challenges. Nature-based solutions to address global societal challenges (IUCN International Union for Conservation of Nature, 2016). doi:10.2305/iucn.ch.2016.13.en

8. Tischew, S., Youtie, B., Kirmer, A. \& Shaw, N. Farming for restoration: Building bridges for native seeds. Ecol. Restor. 29, 219-222 (2011).

9. Nevill, P. G. et al. Seed production areas for the global restoration challenge. Ecol. Evol. 6, 7490-7497 (2016).

10. Broadhurst, L. M., Jones, T. A., Smith, F. S., North, T. \& Guja, L. Maximizing Seed Resources for Restoration in an Uncertain Future. Bioscience 66, 73-79 (2016). 
11. Nieto-Romero, M., Oteros-Rozas, E., González, J. A. \& Martín-López, B. Exploring the knowledge landscape of ecosystem services assessments in Mediterranean agroecosystems: Insights for future research. Environ. Sci. Policy 37, 121-133 (2014).

12. Simoes, M. P., Belo, A. F., Pinto-Cruz, C. \& Pinheiro, A. C. Natural vegetation management to conserve biodiversity and soil water in olive orchards. Spanish J. Agric. Res. 12, 633 (2014).

13. Gómez, J. A. Sustainability using cover crops in Mediterranean tree crops, olives and vines-Challenges and current knowledge. Hungarian Geogr. Bull. 66, 13-28 (2017).

14. Vicente-Vicente, J. L., García-Ruiz, R., Francaviglia, R., Aguilera, E. \& Smith, P. Soil carbon sequestration rates under Mediterranean woody crops using recommended management practices: A meta-analysis. Agric. Ecosyst. Environ. 235, 204-214 (2016).

15. Power, A. G. Ecosystem services and agriculture: tradeoffs and synergies. Philos. Trans. R. Soc. Lond. B. Biol. Sci. 365, 2959-71 (2010).

16. Nunes, A. et al. Ecological restoration across the Mediterranean Basin as viewed by practitioners. Sci. Total Environ. 566-567, 722-732 (2016).

17. Ladouceur, E. et al. Native Seed Supply and the Restoration Species Pool. Conserv. Lett. (2017). doi:10.1111/conl.12381

18. Agencia Andaluza de promición exterior. Estudio del sector del aceite de oliva de Andalucía. (2017).

19. Pujadas Salvá, A. Flora arvense y ruderal de la provincia de Cordoba (Doctoral Thesis). (Universidad de Cordoba, 1986).

20. Paredes, D., Karp, D. S., Chaplin-Kramer, R., Benítez, E. \& Campos, M. Natural habitat increases natural pest control in olive groves: economic implications. J. Pest Sci. (2004). 1-11 (2019). doi:10.1007/s10340-019-01104-w

21. Marshall, E. J. P. et al. The role of weeds in supporting biological diversity within crop fields. Weed Research 43, 77-89 (2003).

22. Sokos, C. K., Mamolos, A. P., Kalburtji, K. L. \& Birtsas, P. K. Farming and wildlife in Mediterranean agroecosystems. J. Nat. Conserv. 21, 81-92 (2013).

23. Frischie, S., Abbandonato, H., Hernández-González, M. \& Gálvez-Ramírez, C. Using seeds to establish native grasses and wildflowers in the understory of a conventional olive orchard. in De Vitis M., Mondoni A., Pritchard H. W., Laverack 

Knowledge and Technology in Europe 104-107 (MUSE, 2018).

24. Abbandonato, H., Pedrini, S., Pritchard, H. W., De Vitis, M. \& Bonomi, C. Native seed trade of herbaceous species for restoration: a European policy perspective with global implications. Restor. Ecol. (2017). doi:10.1111/rec.12641

25. Saatkamp, A. et al. A research agenda for seed-trait functional ecology. New Phytol. 221, 1764-1775 (2019).

26. Nieto, O. M., Castro, J. \& Fernández-Ondoño, E. Sustainable agricultural practices for mediterranean olive grove. Effect of soil management on soil properties. Spanish J. Soil Sci. 2, 70-77 (2012).

27. Gómez, J. A., Sobrinho, T. A., Giráldez, J. V. \& Fereres, E. Soil management effects on runoff, erosion and soil properties in an olive grove of Southern Spain. Soil Tillage Res. 102, 5-13 (2009).

28. De Baets, S., Poesen, J., Knapen, A., Barberá, G. G. \& Navarro, J. A. Root characteristics of representative Mediterranean plant species and their erosionreducing potential during concentrated runoff. Plant Soil 294, 169-183 (2007).

29. Gonzalez-Sanchez, E. J., Veroz-Gonzalez, O., Blanco-Roldan, G. L., MarquezGarcia, F. \& Carbonell-Bojollo, R. A renewed view of conservation agriculture and its evolution over the last decade in Spain. Soil Tillage Res. 146, 204-212 (2015).

30. Carpio, A. J., Castro, J., Mingo, V. \& Tortosa, F. S. Herbaceous cover enhances the squamate reptile community in woody crops. J. Nat. Conserv. 37, 31-38 (2017).

31. Bochet, E. \& García-Fayos, P. Identifying plant traits: A key aspect for species selection in restoration of eroded roadsides in semiarid environments. Ecol. Eng. 83, 444-451 (2015).

32. Aguado Martín, L. Ó., Fereres Castiel, A. \& Viñuela Sandoval, E. Guía de campo de los polinizadores de España. (Munid-Prensa, 2015).

33. European Native Seed Conservation Network. ENSCONET Seed Collecting Manual for Wild Species. 32 (2009). Available at: http://www.ensconet.eu/Download.htm. (Accessed: 21st January 2019)

34. Jiménez-Alfaro, B. et al. Germination ecology of winter annual grasses in Mediterranean climates: Applications for soil cover in olive groves. Agric. Ecosyst. Environ. 262, 29-35 (2018). 
35. Frischie, S. et al. Hydrothermal thresholds for seed germination in winter annual forbs from old-field Mediterranean landscapes. Plant Biol. (2018). doi:10.1111/plb.12848

36. Meier, U. et al. The BBCH system to coding the phenological growth stages of plants - history and publications. J. für Kult. 61, 41-52 (2009).

37. Royal Botanic Gardens Kew. Seed Information Database (SID) Verion 7.1. (2019). Available at: http://data.kew.org/sid/.

38. Rantala-Sykes, B. \& Campbell, D. Should I pick that? A scoring tool to prioritize and valuate native wild seed for restoration. Restor. Ecol. 27, 9-14 (2019).

39. Bohanec, M. DEXi: Program for Multi-Attribute Decision Making, User's Manual, Version 5.00. IJS Report DP-11897. (2015).

40. Craheix, D. et al. Guidelines to design models assessing agricultural sustainability, based upon feedbacks from the DEXi decision support system. Agron. Sustain. Dev. 35, 1431-1447 (2015).

\section{Acknowledgements}

We thank Matías Hernández González for his support on the review of ground cover species and on lab and field work. This research was funded by the PEOPLE/Marie Curie Actions of the European Union's Seventh Framework Programme FP7/20072013/under REA grant agreement $n^{\circ} 607785$ through the ITN project NASSTEC (www.nasstec.eu). B.J.-A. was further supported by the Marie Curie Clarín-COFUND program of the Principality of Asturias and the European Union (ACB17-26) and the Asturias regional grant FC-GRUPIN-IDI/2018/000151.

\section{Contributions}

B.J.-A. and C.G.-R. designed the conceptual framework, focusing on the scientific and agronomic aspects of the study, respectively. S.F. compiled the species data, conducted the agronomic experiments, and created the utility functions. J.S. synthesized all experimental data and calculated the suitability index for all species. B.J.-A. wrote the manuscript with support of S.F. and J.S.

\section{Corresponding author}

Correspondence should be addressed to Borja Jiménez-Alfaro (jimenezalfaro@uniovi.es).

\section{Competing interests}


436 Cándido Gálvez-Ramírez is the head of a private company producing native seeds for 437 ecological restoration.

438 Supplementary Information

439 Supplementary Figures 1-2 and Supplementary Tables 1-2. 
441 covers in Mediterranean olive groves. Olive farming refers to the potential suitability

442 of species to persist in the olive groves without collateral effects on olive viability and

443 production, based on 6 ecological traits. Seed farming refers to the suitability of species

444 to be cultivated in seed farms for producing and harvesting large amount of seeds,

445 based on experimental evidence of 10 production traits. Final suitability summarizes

446 the overall score of the species to be used for ground cover. Other five species that

447 were evaluated did not grow well in the agronomic experiments and were discarded.

\begin{tabular}{|c|c|c|c|c|}
\hline Species & Type & $\begin{array}{l}\text { Olive } \\
\text { farming }\end{array}$ & $\begin{array}{l}\text { Seed } \\
\text { farming }\end{array}$ & $\begin{array}{l}\text { Final } \\
\text { suitability }\end{array}$ \\
\hline Bromus hordeaceus & Grass & Good & Excellent & Excellent \\
\hline Bromus scoparius & Grass & Good & Excellent & Excellent \\
\hline Anisantha madritensis & Grass & Good & Fair & Good \\
\hline Ansisantha rubens & Grass & Good & Fair & Good \\
\hline Hordeum murinum & Grass & Good & Fair & Good \\
\hline Trachynia distachya & Grass & Fair & Excellent & Good \\
\hline Cynosurus echinatus & Grass & Fair & Fair & Fair \\
\hline Lolium mutliflorum & Grass & Fair & Fair & Fair \\
\hline Cleonia lusitanica & Forb & Good & Fair & Good \\
\hline Misopates orontium & Forb & Good & Excellent & Excellent \\
\hline Nigella damascena & Forb & Good & Excellent & Excellent \\
\hline Salvia verbenaca & Forb & Good & Excellent & Excellent \\
\hline Trifolium angustifolium & Forb & Good & Excellent & Excellent \\
\hline Biscutella auriculata & Forb & Good & Fair & Good \\
\hline Capsella bursa-pastoris & Forb & Good & Excellent & Excellent \\
\hline Echium plantagineum & Forb & Fair & Good & Fair \\
\hline Glebionis segetum & Forb & Fair & Excellent & Good \\
\hline Medicago orbicularis & Forb & Good & Fair & Good \\
\hline Medicago polymorpha & Forb & Good & Fair & Good \\
\hline Moricandia moricandioides & Forb & Fair & Excellent & Good \\
\hline Papaver dubium & Forb & Good & Fair & Good \\
\hline Silene colorata & Forb & Good & Good & Good \\
\hline Stachys arvensis & Forb & Fair & Excellent & Good \\
\hline Tordylium maximum & Forb & Fair & Excellent & Good \\
\hline Trifolium hirtum & Forb & Good & Fair & Good \\
\hline Trifolium lappaceum & Forb & Good & Fair & Good \\
\hline Trifolium stellatum & Forb & Excellent & Fair & Good \\
\hline Vaccaria hispanica & Forb & Fair & Excellent & Good \\
\hline Anthemis cotula & Forb & Fair & Fair & Fair \\
\hline Calendula arvensis & Forb & Excellent & Poor & Fair \\
\hline Crepis capillaris & Forb & Fair & Fair & Fair \\
\hline Scabiosa atropurpurea & Forb & Fair & Fair & Fair \\
\hline Silene gallica & Forb & Fair & Good & Fair \\
\hline Tolpis barbata & Forb & Fair & Poor & Poor \\
\hline Anthyllis vulneraria & Forb & Good & Poor/Fair & Fair/Good \\
\hline
\end{tabular}


450 agroecosystem restoration. For a given study system, this process is based on the

451 assessment of ecological and production traits of wild species known to occur in a

452 target habitat (the 'agroecosystem species pool'). The ultimate goal is to set species

453 priorities for seed farming towards the large-scale production of seeds (the 'restoration

454 species pool'). This research agenda shall be tied to policy targets (e.g. the actions

455 derived from the United Nations Decade on Ecosystem Restoration for 2021-2030) and

456 restoration practice (e.g. the promotion of seed banks for native species and

457 regeneration of ground cover by conservation agencies or private companies).

\section{RESEARCH AGENDA}

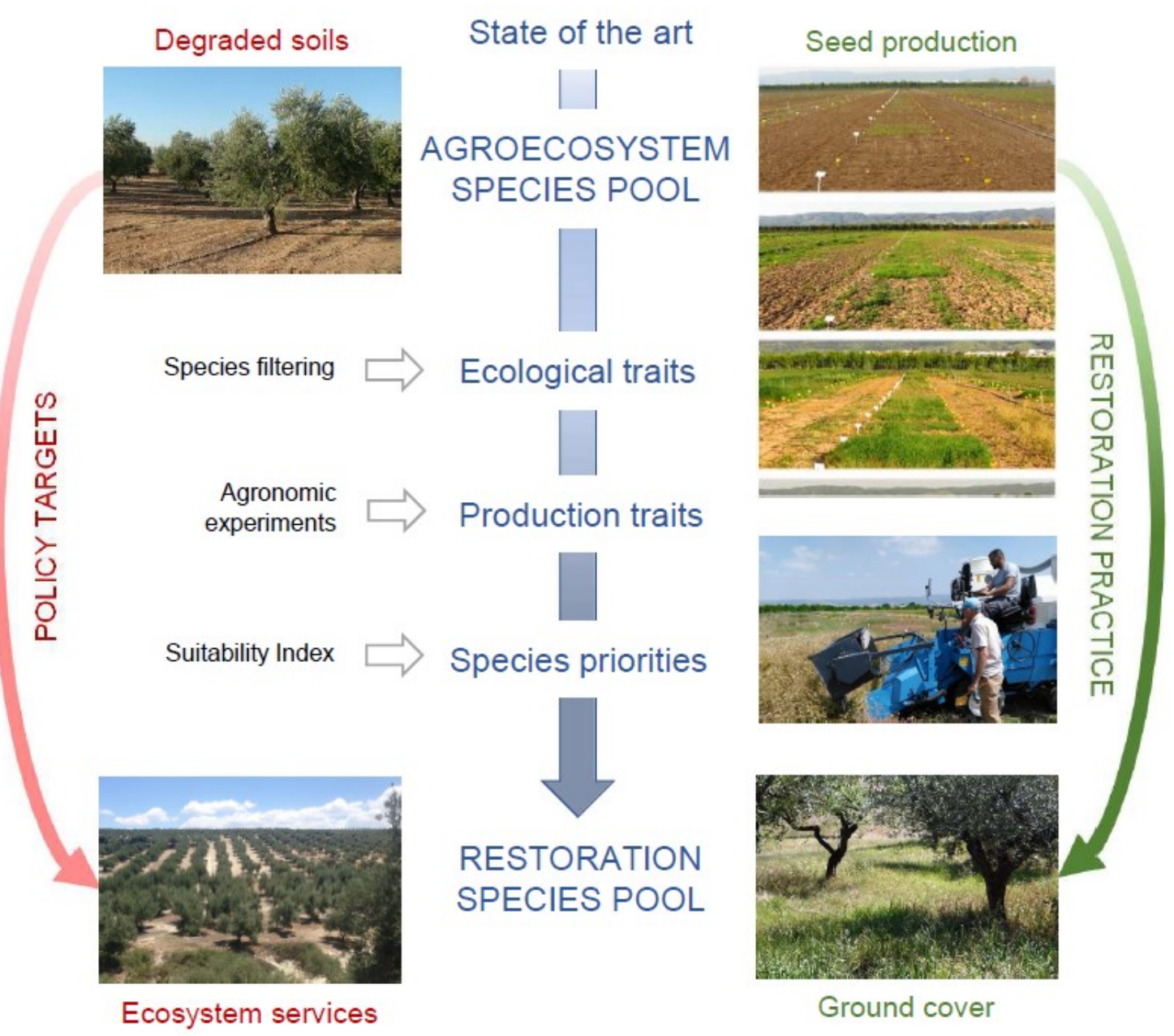


460 Mediterranean olive groves during the period 1985-2015. a, Number of publications

461 dealing with major topics identified in 50 studies reviewed for the study system,

462 showing the proportion of commercial or native species (evaluated 79 and 24 times,

463 respectively). Publications dealing with more than one research topic are counted

464 multiple times. "Biodiversity" refers to studies dealing with the diversity of plant species

465 and their interactions with animals or microorganisms. b, Proportion of botanical

466 families represented in the reviewed studies for the subsets of commercial $(N=42)$

467 and native $(\mathrm{N}=20)$ species.

a Ecosystem services
Management guidelines
Impact on olive production
Impact on soil characteristics
Impact on soil erosion
Impact on soil water
Groundcover performance
Prevention of pests
Species-based review
Remote-sensing mapping
Weed prevention

468 b Commercial species

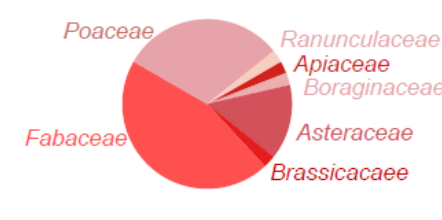

Native species

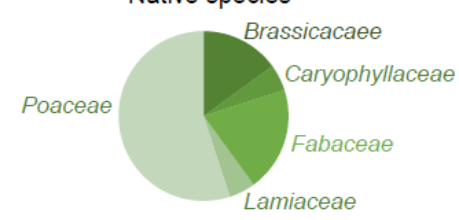


470 fields for seed farming. Each species is characterized with measurements taken

471 every two weeks from February $(F)$ to July $(J)$, indicating the phenological growth

472 stages from germination/resprouting (0) to senescence (9) as indicated by the color

473 palette. Growth stages were adapted from the "Biologische Bundesanstalt,

474 Bundessortenamt und $\mathrm{CHemische}$ Industrie" (BBCH) system to coding the phenology

475 of plants ${ }^{36}$. The species were grown in an agricultural area with potential to be used for

476 seed farming of native species in Córdoba province, Andalusia, Spain.

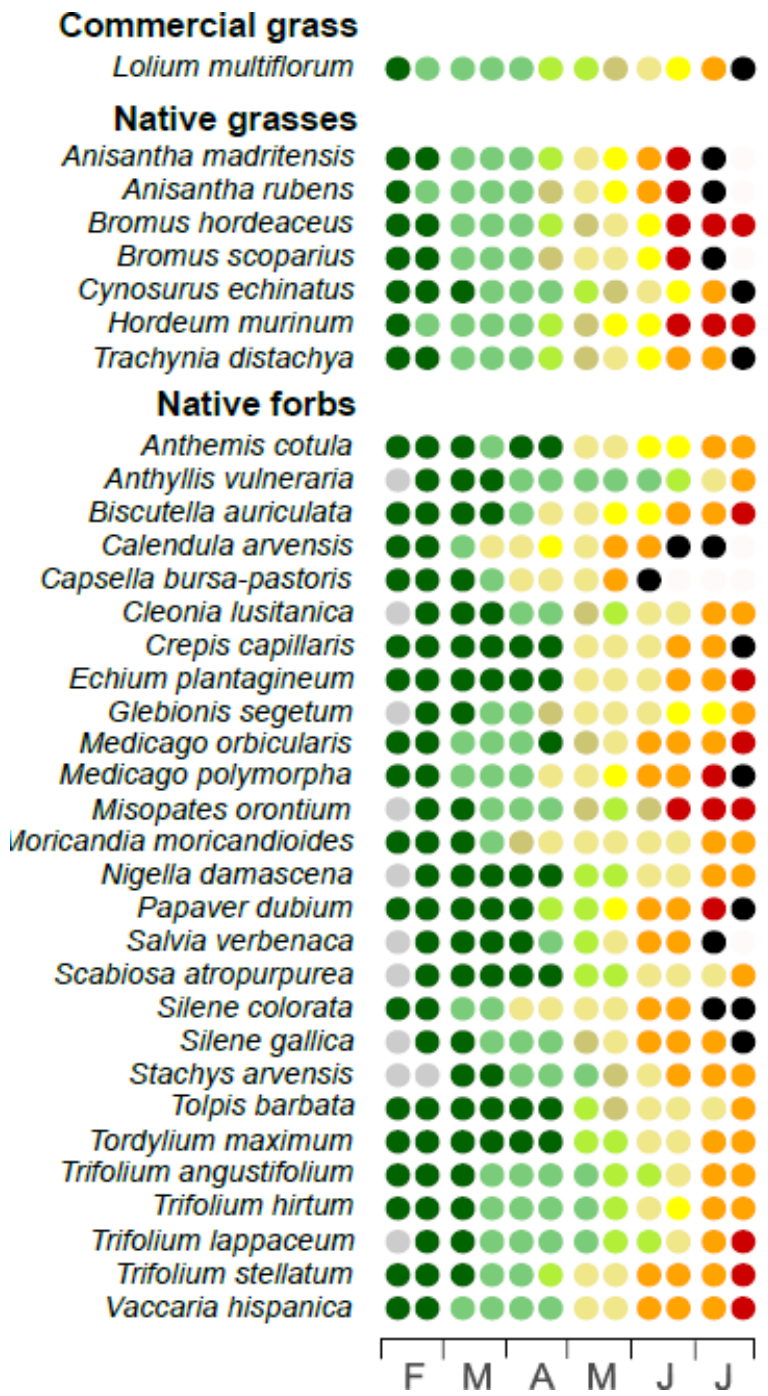

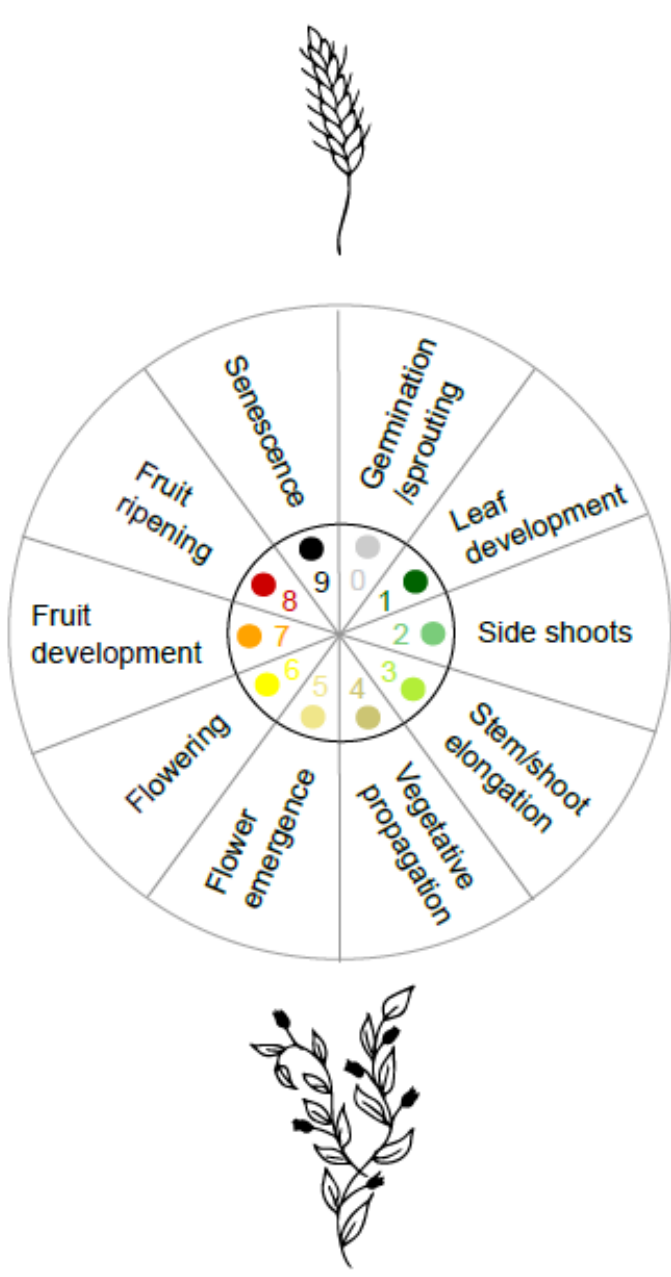

477 